Journal of Applied Biology \& Biotechnology Vol. 5 (01), pp. 010-017, Jan-Feb, 2017

Available online at http://www.jabonline.in

DOI: $10.7324 / \mathrm{JABB} .2017 .50102$

(c) $\mathrm{BY}-\mathrm{NC}-\mathrm{SA}$

\title{
Over-expression of Id2 and Id3 Proteins Regulates Growth and Survival of Human Colon Carcinoma (HCT116) Cells
}

\author{
Foster Kyei $^{1 *}$, Du-Bois Asante ${ }^{2}$, Esther Sarpong ${ }^{1}$, Juliet Ama Mawusi Edekor ${ }^{1}$, Daniels Konja ${ }^{2}$, Edem Gavor ${ }^{1}$ \\ ${ }^{1}$ College of Agriculture and Natural Sciences, School of Biological Sciences, Department of Molecular Biology and Biotechnology, University of Cape \\ Coast, Cape Coast, Ghana. ${ }^{2}$ College of Health and Allied Sciences, School of Allied Sciences, Department of Forensic Sciences, University of Cape Coast, \\ Cape Coast, Ghana.
}

\section{ARTICLE INFO}

Article history:

Received on: $22 / 10 / 2016$

Revised on: 09/11/2016

Accepted on: 30/11/2016

Available online: 20/01/2017

Key words:

Apoptosis, Neoplastic, Lossof-function, Gain-of-

function, Phosphorylation.

\begin{abstract}
Inhibitor of differentiation (Id) proteins are members of the Helix-Loop-Helix (HLH) group of transcription factors. These proteins uniquely have no DNA-binding domain and they play vital roles in cell growth, differentiation, senescence, apoptosis, angiogenesis and neoplastic transformation. Objective: This work investigated the pro-apoptotic functions of Id proteins and their loss-or gain-of function mutants to delimit the functional domains that are essential for apoptosis in an in vitro model using human epithelial colon carcinoma cell line (HCT116). Plasmids encoding Id1, Id2, Id3 and Id4 proteins were transiently over-expressed in cultured HCT116. Initially, cell proliferation assay with MTT (3-(4, 5-Dimethylthiazol-2-yl)-2, 5- diphenyltetrazolium bromide) was performed, followed by apoptotic and cell cycle analyses on the transfected cells. Apoptotic and cell cycle profiles were generated and statistically analyzed. Id3 protein exhibited a pro-apoptotic effect in colorectal cancer cell lines (HCT116). In addition, over-expression of Id3 resulted in growth arrest in HCT116. Id 2 Asp5 showed a pro-apoptotic whilst Id2 Ala5 and Id 2 HB enhanced viability of HCT116. These findings suggest that Id2 Asp5 may be loss-of-function mutant in HCT116 lines. The aspartate mutant of Id3 (Id3 Asp5) was observed to be pro-apoptotic. However Id3 Ala5 and Id3 HB showed an anti-apoptotic effect. These findings suggest that Id2 Asp5, Id3 Ala5, Id3 HB and Id3NLS may be loss-of-function mutants in HCT116 whilst Id2 Ala5, Id2 HB and Id3 Asp5 are gain-of-function mutants. These results may suggest that Id2 and Id3 may play essential roles in modulating human epithelial colon carcinoma growth and survival and could provide some hope for therapeutic opportunities in the treatment of colonic cancers.
\end{abstract}

\section{INTRODUCTION}

Id proteins are involved in the regulation of molecular networks and other cellular processes such as cell growth, differentiation, senescence, apoptosis, angiogenesis and neoplastic transformation and tumourigenesis [1]. Literature also suggests that inappropriate entry of cells into S-phase is associated with apoptosis; hence these two cellular activities are coordinately

\section{* Corresponding Author}

Foster Kyei, College of Agriculture and Natural Sciences, School of

Biological Sciences, Department of Molecular Biology and

Biotechnology, University of Cape Coast, Cape Coast, Ghana.

Email:fkyei @ ucc.edu.gh regulated [2,3]. There is evidence that many genes have products that regulate cell cycle progression and also play a pivotal role in the modulation of apoptosis [3]. However, recent investigations have demonstrated that dual regulators of proliferation and apoptosis promote these processes by a separate mechanism [3]. To support this, reports also implicate p53, the tumor suppressor protein, which can induce growth arrest as well as apoptosis are genetically separable [4].

The above findings imply that whilst regulators of cell death and growth pathways are shared and coordinated, their functional activities in these pathways are distinct [5]. Of recent, much emphasis has been laid on the pro-apoptotic properties of Id proteins and several reports support the pro-apoptotic characteristics of Id proteins. Tumor tissues compared with normal intestinal mucosa showed high levels of Id1, Id2 and Id3 proteins [6]. 
Recent evidence suggests that Id1 and Id3 play pivotal roles in regulating developmental and postnatal angiogenesis [7]. Id proteins play a role in the regulating of cell growth and differentiation when over-expressed and have also been implicated to induce malignant transformation [6]. It has been observed that enforced expression of Id genes in vivo could also induce apoptosis. Over-expression of Id1 in dense mammalian cell cultures shows a pro-apoptotic response [8]. Also, it has been revealed that Id 3 expression induces apoptosis in astrocyte-derived cell line [9] whereas over-expression of Id1 induces apoptosis in neonatal and adult cardiac myocytes through a redox-independent mechanism [10]. $1 \mathrm{~d} 2$ is involved in apoptosis in a pathway that is different from what has been identified with the other Id family of proteins [11]. Evidence available shows that Cyclin A- and Cyclin E-dependent CDK2 phosphorylation of the Id2 and Id3 proteins at a conserved serine residue at position 5 regulates the ability of these proteins to antagonize bHLH-dependent gene expression [12].

Given the above roles that Id proteins play in inducing apoptosis, the findings have raised the hopes that Id proteins could be a target for cancer therapy since it is evident that these proteins play significant roles in inducing malignant transformation when ectopically expressed.

Hence, this work aimed at investigating the pro-apoptotic functions of Id proteins and their loss-or gain-of function mutants to delimit the functional domains that are essential for apoptosis in an in vitro model using human epithelial colon carcinoma cell line (HCT116). This objective was achieved by over-expressing plasmids encoding Id1, Id2, Id3 and Id4 proteins in HCT116.

\section{MATERIALS AND METHODS}

\subsection{Adherent cell culture}

The Human epithelial colon carcinoma cell line (HCT116) (American Type Culture Collection, USA) was cultured as described previously [13].

\subsection{Transfection of adherent cells}

$8 \times 10^{4} /$ well of HCT116 Cells were plated the day before transfection in a 24-well plate. The following day prior to preparation of transfection mix, the old medium on cells was carefully removed and $0.5 \mathrm{ml}$ of fresh serum-containing medium (without antibiotics) was added onto the cells. The plate was then returned into the incubator.

In one tube, $1 \mu \mathrm{g}$ of either control vector (pcDNA3) or Id1, Id2, Id3 Id4, Id mutants and aHLH (gene regulation laboratory, University of Essex, England) was added to $25 \mu \mathrm{l}$ Hepes Buffered Saline (HBS) (Synovolux Therapeutics, Groningen, Netherlands) solution and mixed gently. The DNAHBS mixture was allowed to incubate at room temperature for 5 min. In a separate tube, $4 \mu \mathrm{l}$ of Saint 18 reagent (Synovolux Therapeutics, Groningen, Netherlands) was added to $25 \mu$ l HBS. The DNA/HBS solution was then added to the Saint 18/HBS solution and mixed gently. The mixture was allowed to incubate for $15 \mathrm{~min}$ at room temperature. The whole transfection mixture was added drop-wise and evenly onto the cells. The plate was returned into the incubator. After $3.5 \mathrm{hr}$ of transfection, the growth medium on cells was carefully removed and replaced with $0.5 \mathrm{ml}$ of fresh complete medium.

The cells were again returned into the $\% 5 \mathrm{CO}_{2}$ incubator at $37{ }^{\circ} \mathrm{C}$. In 12-well plates, the volumes of transfection reagent and plasmid DNA were scaled-up by a factor of 2 (thus $2 \mu \mathrm{g}$ of plasmid DNA, $50 \mu 1$ of HBS, $8 \mu 1$ of Saint 18 reagent and the medium on cells was $1 \mathrm{ml}$ ).

\subsection{Cell proliferation assay}

Cell proliferation assay with MTT (3-(4, 5Dimethylthiazol-2-yl)-2, 5-diphenyltetrazolium bromide) assay (Sigma-Aldrich, USA) was performed to evaluate the proliferative activity of HCT116 cells. Using a 24-well plate, $25 \mu$ of the MTT working stock $(10 \mathrm{mg} / \mathrm{ml})$ was added directly and evenly onto cells cultured in $0.5 \mathrm{ml}$ of complete growth medium. The methodology followed is elaborated in earlier study [13].

\subsection{Cell cycle assay}

Cell cycle profiling using Hoechst dye stain and EdU (5ethynyl-2-deoxyuridine) ("Click-It EdU”, Invitrogen, USA) was used to evaluate cell cycle parameters of HCT116. The DNA contented analysis was performed as outlined previously [13]. Data from the flow cytometer were analyzed using Windows Multiple Document Interface Software version 2.9. Subpopulations of cells were gated and quantified from the profiles generated.

\subsection{Cell death analysis}

Apoptotic, necrotic and viable populations of HCT116 cells were determined by DiOC6 (3, 3'-dihexyloxacarbocyanine iodide) (Invitrogen, USA) counter-stained with PI as previously described [13].

Data from the flow cytometer were also analyzed using Windows Multiple Document Interface Software version 2.9. Subpopulations of cells were gated and quantified from the density plots generated.

\subsection{SDS-PAGE protein electrophoresis, western blot and statistical analyses}

HCT116 cell lysates were prepared for SDS-PAGE analysis followed by a West blot as described previously [13]. Data obtained were statistically analyzed using online available tool (http://faculty.vassar.edu/lowry/VassarStats.html). The probability $(\mathrm{P})$ values were then calculated for the significance of the difference between the test and control proportions. Also student $t$-test was used to compare the significance of the difference between controls and test samples. Differences were considered to be statistically significant at $\mathrm{P}<0.05(*)$, highly significant at $\mathrm{P}<0.001(* *)$, very highly significant at $\mathrm{P}<0.0001$ (***). 
A

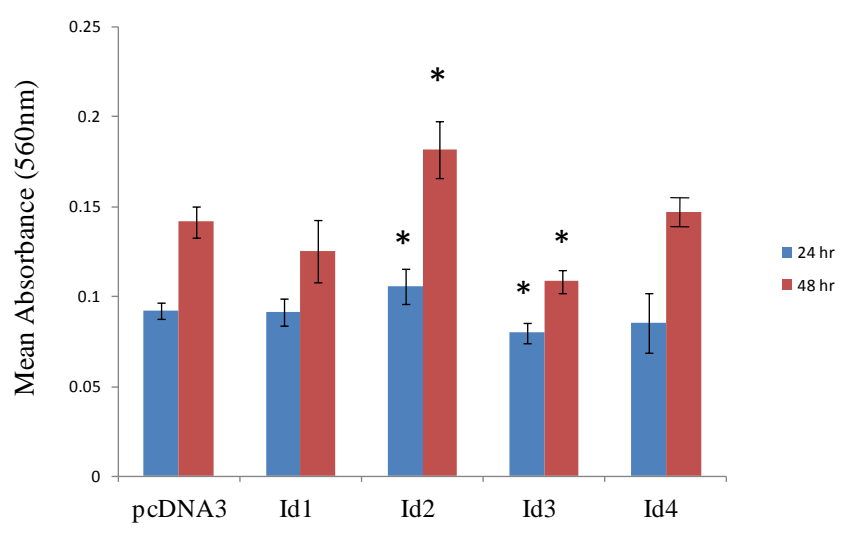

B

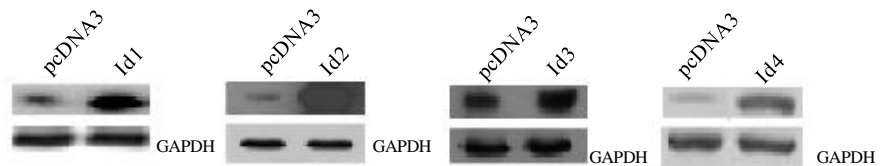

Fig. 1A: Cell viability analysis of HCT116 cells with MTT assay showing relative viable cell numbers in Id1-4 transfectants at 24 and 48 hr post-transfection. Cells were transfected with either control vector (pcDNA3) or Id1, Id2, Id3 and Id4 using Saint 18 reagent. B: Western blot analysis showing endogenous and over-expressed levels of Id proteins (Id1-4). GAPDH was used as loading control. Means \pm S.E.M of 3 separate experiments.

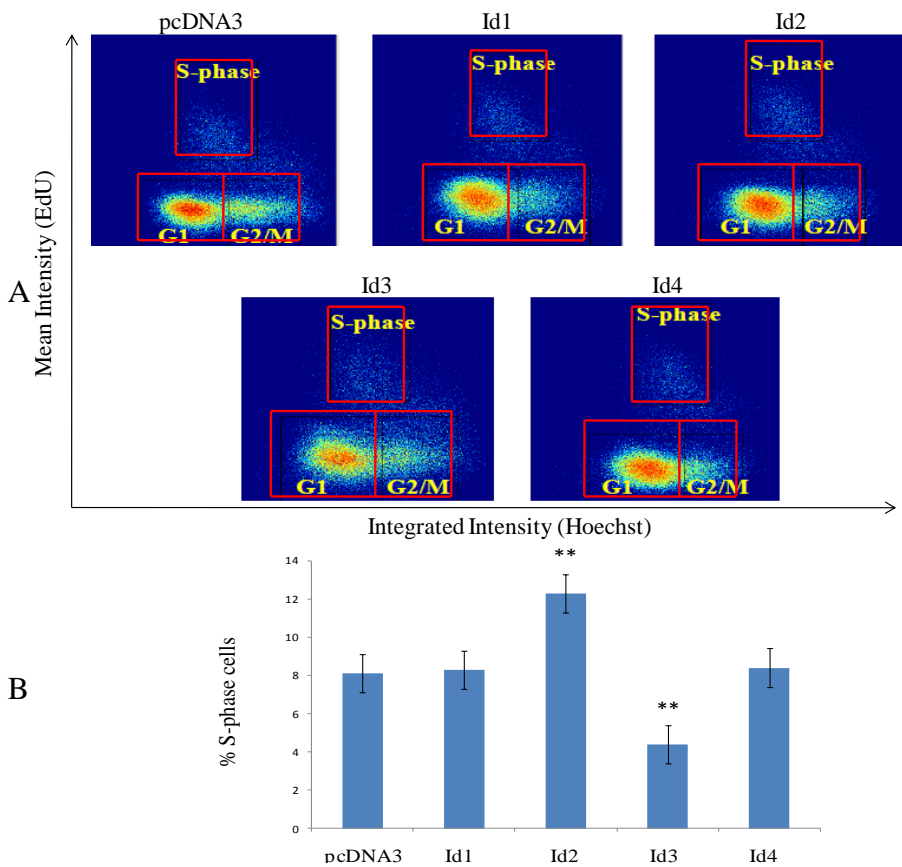

Fig. 2: Cell cycle analysis showing gated G1, S-phase and G2/M populations of HCT116 transfected with either control vector (pcDNA3) or Id1, Id2, Id3 and Id4 proteins at $48 \mathrm{hr}$ post-transfection using Saint 18 reagent. A: Cell cycle profiles generated for each transfection using Cell Profiler Analyst Software. B: Bar graph showing percentage S-phase populations.

\section{RESULTS}

\subsection{Id2 and Id3 proteins affect cell viability in HCT116 cells}

In 24-well plates, $2 \times 10^{4}$ /well of HCT116 cells were propagated in quadruplets and transfected with pcDNA3, Id1, Id2, Id 3 and Id4 using Saint 18 reagent. MTT assay was performed on the cells at 24 and $48 \mathrm{hr}$ post-transfection. The absorbance values were then measured spectrophotometrically. The results showed a significant reduction in viable and proliferating HCT116 cells transfected with Id 3 at both 24 and $48 \mathrm{hr}$ post-transfection whilst the Id2 transfectants significantly enhanced viability (Fig. 1).
However, Id 1 and Id 4 did not show any significant viability effect after $24 \mathrm{hr}$ and $48 \mathrm{hr}$ of transfection.

\subsection{Id2 drives s-phase whilst Id3 arrests s-phase cells}

Following earlier results that implicate Id 3 to reduce the viable populations of HCT116, it was again important to also investigate whether the reduction of proliferating cells by $\mathrm{Id} 3$ with MTT is also mediated through suppression of S-phase cells. Here, $8 \times 10 \%$ well of HCT116 cells were propagated in 12 -well plates followed by transfecting with either control vector (pcDNA3) or Id1, Id2, Id3 and Id4. It was observed that over-expression of Id2 
drives S-phase whilst ectopic expression of Id3 suppresses S-phase in HCT116. However, Id1 and Id4 displayed an activity not different from control pcDNA3 (Fig. 2).

\subsection{Id3 induces apoptosis in HCT116}

It was necessary to investigate whether the reduction in viable HCT116 cells is also as a result of pro-apoptotic functions of Id3 proteins. HCT116 were over-expressed with either control vector pcDNA3 or Id1, Id2, Id3 and Id4. At 24 and 48 hr posttransfections, the cells were incubated in DiOC6 stain and counterstained with Propidium Iodide (PI). Cells were processed through the flow and the apoptotic population for each transfection was evaluated. Comparing the Id constructs and the negative control pcDNA3, the results showed significant induction of apoptosis by Id3 (flow data not shown), suggesting that Id3 is pro-apoptotic. However, Id1, Id 2 and Id4 transfectants were not different from the control (Fig. 3).

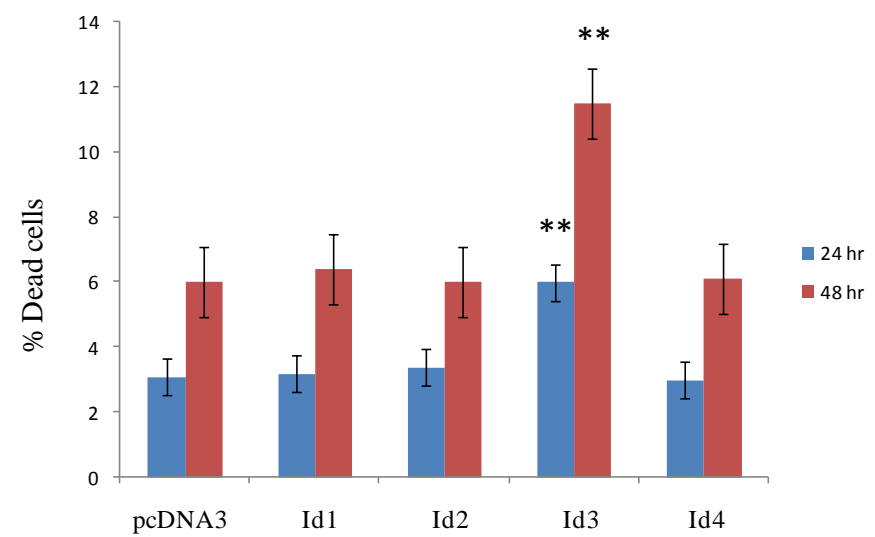

Fig. 3: Percentage apoptotic populations in HCT116 cells at 24 and $48 \mathrm{hr}$ posttransfection. Cells were transfected with negative control vector (pcDNA3) or Id2, Id2, Id3 and Id4 using Saint 18 reagent and Stained with DiOC6 dye. Cells were counter-stained with PI at $2.5 \mathrm{mg} / \mathrm{ml}$ on ice and processed through the flow. Means \pm S.E.M of 3 separate independent experiments.

\subsection{Id3 Asp5 is pro-apoptotic and gain-of-function mutant whilst Id3 Ala5, Id3 HB and Id3 NLS are loss-of-function mutants in HCT116}

To investigate the effects of loss-or gain-of-function mutations of Id3 protein in HCT116 cells, selective variants of Id3 protein in which loss-or gain-of function mutations have been introduced were assessed for their pro-apoptotic functions. Here, Id3 (wt), Id3 Ala5, Id3 Asp5, Id3 HB and Id3 NLS mutants were transfected using Saint 18 reagent in $2 \times 10^{4} /$ well of HCT116 cells. MTT assay was performed on the cells at 24 and $48 \mathrm{hr}$ posttransfection. Id3 (wt) and Id3 Asp5 mutant significantly reduced the number of viable HCT116 cells. On the other hand, Id3 Ala5, Id3 HB and Id3 NLS rather enhance cell viability. Hence Id3 Asp5 acts as gain-of-function mutant whilst Id3 Ala5, Id3 HB and Id3 NLS are loss-of-function mutants at both 24 and $48 \mathrm{hr}$ posttransfection in HCT116 (Fig. 4). Western blot analysis illustrating expression levels of endogenous Id3 and transient transfection of Id3 wt and its mutants in are also shown in figure 4. The western blot analysis shows that transient transfection of Id3 wt and its mutants resulted in the over-expression of these proteins in HCT116.

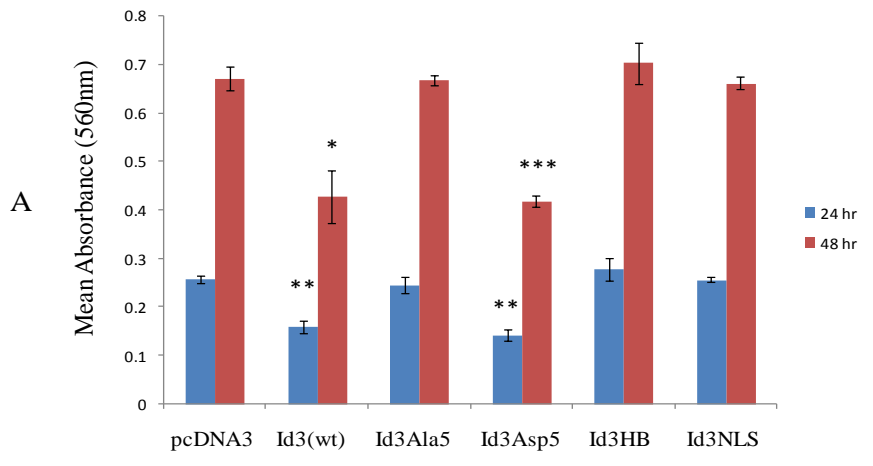

B

GAPDH

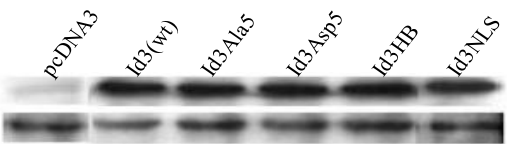

Fig. 4: Cell viability analysis of HCT116 with MTT assay showing relative viable cell numbers transfected with either control vector (pcDNA3) or Id3 (wt), Id3 Ala5, Id3 Asp5, Id3 HB and Id3 NLS using Saint 18 reagent after 24 and $48 \mathrm{hr}$ A: Bar graph showing corresponding absorbance values when cells were incubated in MTT assay for two hr and solublized in DMSO after 24 and $48 \mathrm{hr}$ of transfection (with Id3 wt and mutants). B: Western blot analysis showing relative expression levels of endogenous Id3 wt and over-expressed levels compared to its mutants (Id3 Ala5, Id3 Asp5, Id3 HB and Id3 NLS) GAPDH was used as loading control. Mean absorbance \pm S.E.M of 4 separate/independent samples respectively for each transfection.

\subsection{Id2 Asp5 is pro-apoptotic and a loss-of-function mutant whilst Id2 Ala5 and Id2 HB Function as gain-of-function mutants in HCT116}

Next was to investigate the pro-apoptotic functions of Id2 wt and its mutants as described previously. The Id constructs transfected here were Id2 (wt), Id2 Ala5, Id2 Asp5, and Id2 HB, all compared to negative control pcDNA3 at 24 and $48 \mathrm{hr}$ posttransfection. The results revealed that Id2 Asp5 significantly reduces population of viable HCT116. The results also show that Id 2 wt, Id 2 Ala5 and Id3 HB enhanced the viability of HCT116. Hence Id2 Asp5 is pro-apoptotic and a loss-of-function mutant whilst Id2 Ala5 and Id2 HB behave as gain-of-function mutants. Western blot analysis illustrating expression levels of endogenous Id 2 and transient transfection of Id 2 wt and its mutants in are shown (Fig. 5).

To investigate whether the reduction in number of viable cells shown by Id3 wt, Id3 Asp5, Id2 Asp5 as shown with MTT in HCT116 (Fig. 4 and 5) is due to induction of apoptosis, an independent cell death marker (DiOC6) was used to evaluate the populations of apoptotic and necrotic cells at 24 and $48 \mathrm{hr}$ posttransfection. In this approach, $8 \times 10^{4} /$ well of HCT116 cells were seeded in 12-well plates and over-expressed with either pcDNA3 or Id 2 wt, Id2 Asp5, Id3 wt, Id3 Asp5.Comparing the Id constructs with the negative control pcDNA3, the results showed significant induction of apoptosis with Id2 Asp5, Id3 wt, Id3 and Id3 Asp5 transfectants at both 24 and $48 \mathrm{hr}$ post-transfection (Fig. 6). The above results confirm earlier observations of the ability of Id3 wt, 
Id3 Asp5 and Id2 Asp5 in reducing viable populations of HCT116 cells using MTT (Fig. 4 and 5). Hence Id3 wt, Id3 Asp5 and Id2 Asp5 are apoptotic and therefore Id3 Asp5 is a gain-of-function mutant whilst Id2 Asp5 is a loss-of-function mutant.

A

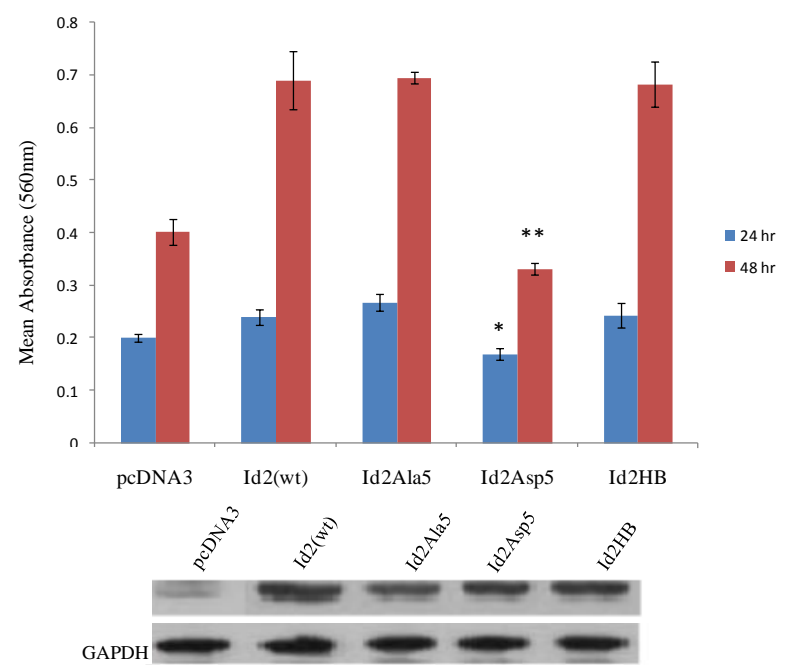

Fig. 5: Cell viability analysis of HCT116 with MTT assay showing relative viable cell numbers transfected with either control vector (pcDNA3) or Id2 (wt), Id2 Ala5, Id2 Asp5 and Id2 HB using Saint 18 reagent at 24 and $48 \mathrm{hr}$ post-transfection. A: Bar graph showing corresponding absorbance values when cells were incubated in MTT assay for two hours and solublised in DMSO after 24 and $48 \mathrm{hr}$ of transfection (with Id2 wt and mutants). B: Western blot analysis showing relative expression levels of endogenous Id2 wt and over-expressed levels compared to its mutants (Id2 Ala5, Id2 Asp5 and Id2 HB). GAPDH was used as loading control. Mean absorbance \pm S.E.M of 4 separate/independent samples respectively for each transfection.

\section{DISCUSSION}

This work investigated the ability of Id proteins and its mutants in inducing apoptosis and their involvement in cell cycle progression in human epithelial colon carcinoma cell line (HCT116). Using MTT assay, over-expression of Id1-4 showed significant reduction in viability with Id3 transfectants whilst Id1, Id2 and Id4 showed protective effect (Fig. 1). Cell cycle analysis following Id3 over-expression resulted in S-phase arrest (Fig. 2), hence the reduction in viability by ectopic expression of Id3 in HCT116 is mediated through S-phase arrest. However Id2 drove S-phase cells (Fig. 2). Ectopic expression of Id3 in pre-B cells resulted in loss of cells from the S-phase of the cell cycle. Hence Id3 inhibits expression of multiple genes involved in varied aspects of B lymphocyte proliferation and induces growth arrest in B lineage cells [14].

Over-expression of Id 3 also resulted in marked cell death, hence reduced viability as observed with MTT is also mediated through apoptosis (Fig. 3). Over expression of Id3 protein in B lymphocyte progenitor cells induced apoptosis [14]. Conversely, recent data on primary Human Vein Umbilical Endothelial Cells show that over-expression of Id3, but not Id 1 can protect HUVECs from apoptosis [15]. Apoptosis induction by Id proteins has been found to be complex in different variety of cell types [16]. However, Id proteins have been shown to have antiapoptotic activity [17] as observed with Id2 in this study.
Inappropriate entry of cells into S-phase is associated with apoptosis; hence these two cellular activities are coordinately regulated $[2,3]$. There is evidence that many genes have products that regulate cell cycle progression and also play a pivotal role in the modulation of apoptosis. Recent investigations have demonstrated that dual regulators of proliferation and apoptosis promote these processes by a separate mechanism [3]. To support this argument, several reports also implicate p53, the tumor suppressor protein, which can induce growth arrest as well as apoptosis to be genetically separable [4]. The above findings imply that whilst regulators of cell death and growth pathways are shared and coordinated, their functional activities in these pathways are distinct [5].

The biochemical and genetic analysis of mammals show that Id proteins function basically through antagonism of the bHLH transcription factors [11], and the changes that occur in the equilibrium of heterodimeric interactions between the Id proteins and the bHLH counterparts causes changes in cell determination and function [18]. The above results suggest that Id3 may weakly associate with its bHLH counterpart and therefore ineffectively forms Id-bHLH heterodimers. Hence it is not able to efficiently antagonize the functions of the bHLH proteins thereby abrogating its pro-growth properties leading to widespread cell death and growth arrest in tumourigenic epithelial colon cancer cell (HCT116).

Id3 expression induces apoptosis in astrocyte-derived cell line [9]. It has also been shown that Id3-overexpression in primary rat embryo fibroblasts (REF) cell lines alone or with the antiapoptotic Bcl2 and BclXL oncogenes induced apoptosis and this observation suggests that Id 3 in isolation might induce cell death [19]. Id family of proteins has been generally shown to promote apoptosis in a variety of conditions [1]. Pro-apoptotic properties on loss-or gain-of-function of Id2 and Id3 in human epithelial colon carcinoma cell line (HCT116) were investigated. The results showed that transient expression of Id3 wt and Id3 Asp5 reduced the number of viable cells (Fig. 4) and induced apoptosis (Fig. 6), hence Id3 Asp5 may be pro-apoptotic, suggesting that Id3 Asp5 may be a gain-of-function mutant. However Id3 Ala5, Id3 HB and Id3 NLS neither increased the population of viable cells nor induce apoptosis; hence may act as loss-of-function mutants (Figure 4). Protein phosphorylation is a post-translational modification mechanism, which either inhibits or promotes the activity of a protein. It can also change the function or localization of a protein. Evidence available suggests that Id proteins are localized in the cytoplasm rather than the nucleus in a variety of cells such as hemopoietic [20], neural [21], muscle [22], and renal cells [23]. These findings therefore suggest that translocation between the nucleus and the cytoplasm (nucleocytoplasmic shuttling) may be involved in the functional regulation of Id proteins. It has also been observed that nucleocytoplasmic shutting is mediated by the nuclear pore complex in which the importin and CRM1/exportin family promote nuclear import and export by binding cargo through the recognition of nuclear import (NLS) and export sequences (NES) [24]. 


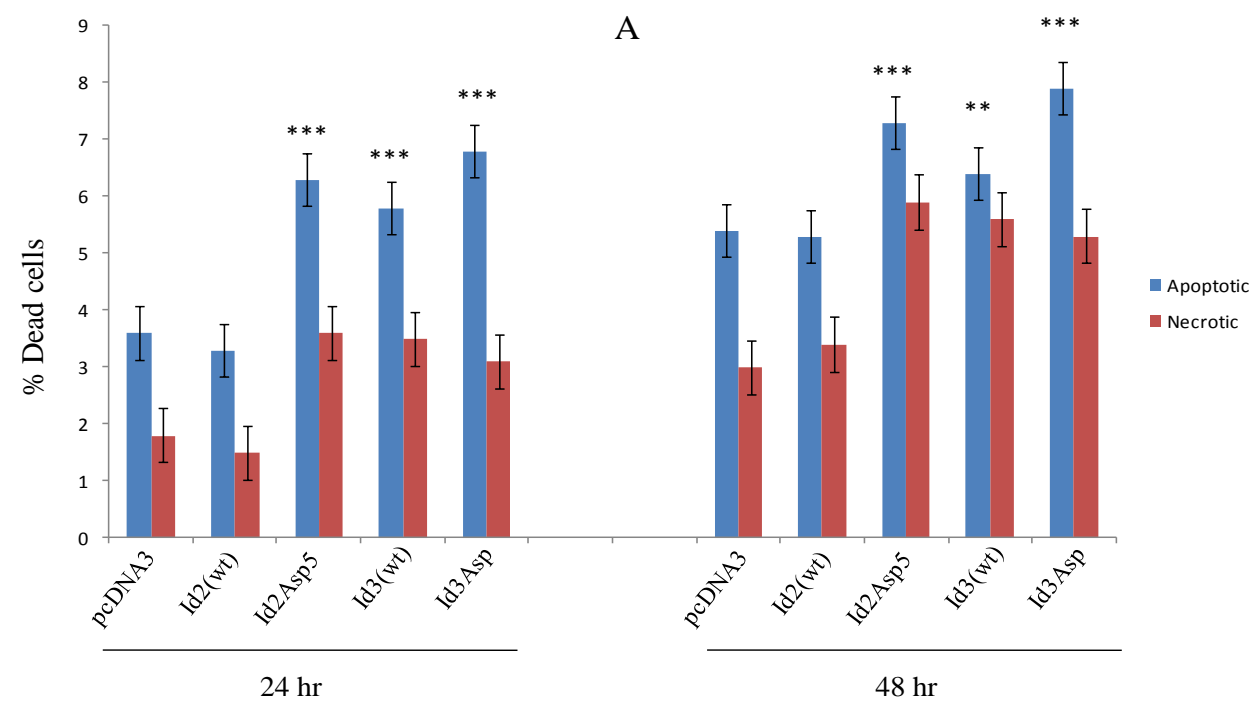

B

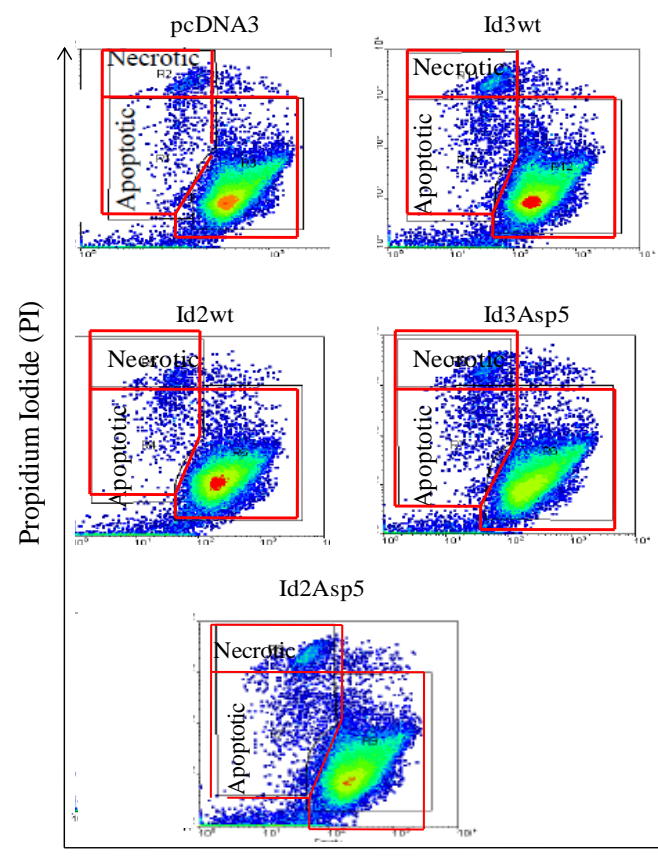

$\mathrm{C}$
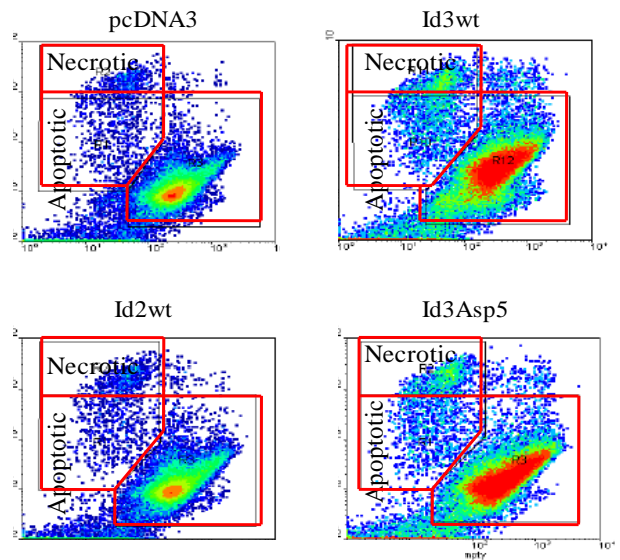

Id2Asp5

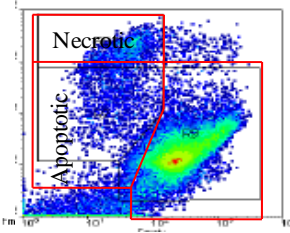

DiOC6

Fig. 6: Dead cell populations of HCT116 cells at 24 and $48 \mathrm{hr}$ post-transfection. A: Bar graph showing percentage apoptotic and necrotic cells transfected with negative control vector (pcDNA3) or Id2 wt, Id2 Asp5, Id3 wt and Id3 Asp5 using Saint 18 reagent and Stained with DiOC6 dye. Cells were counter-stained with PI at $2.5 \mathrm{mg} / \mathrm{ml}$ on ice. Means \pm S.E.M of 3 separate independent experiments. Flow cytometric analysis showing gated apoptotic and necrotic populations of HCT116 cells at $24 \mathrm{hr}$ (B) and $48 \mathrm{hr}$ (C) post-transfections transfected with either control vector (pcDNA3) or Id2 wt, Id2 Asp5, Id3 wt and Id3 Asp5.

As Id2, Id3 and Id4 are substrates for the CDK2dependent phosphorylation of the conserved serine 5 residue during later G1/early $\mathrm{S}$ phase [12,25], there is alteration in the bHLH dimerization specificity of Id2 and Id3 proteins. This is important for cell cycle progression since mutants of Id2 and Id3 without CDK2 phosphorylation show S-phase arrest and cell death [25]. It has been shown that unphosphorylated form of Id3 (normally present throughout early G1) but not the phosphorylated form (persisting from late G1 throughout $\mathrm{S}$ phase of the cell cycle) drives apoptosis [19]. Again, prevention of CDK2-dependent phosphorylation of transfected Id 3 by using the Id3 Ala5 mutant significantly enhanced both cell cycling and apoptotic responses in primary rat embryo (REF) cells [19]. By comparing phosphomimicking Id3 mutant (Id3 Asp5), phospho-ablated mutant (Id3 
Ala5) and Id3 (wt), Id3 Asp5 mutant suppresses S-phase cells whereas Id3 Ala5 mutant drives S-phase cells but associated with cell death in primary rat embryo fibroblasts [25]. With the Id2 constructs, Id2 Asp5 showed a pro-apoptotic function, hence behaves as a loss-of-function mutant whilst Id2 Ala5 and Id2 HB are gain-of-function mutants in HCT116 as shown by MTT (Fig. 5) and independent cell death marker DiOC6 (Fig. 6). Conversely, it has been reported that phosphor-ablated Id2 (Id2 Ala5) is growth suppressive and pro-apoptotic in proliferating myoblasts [26]. Evidence available shows that Cyclin A- and Cyclin E-dependent CDK2 phosphorylation of $\operatorname{Id} 2$ and Id 3 proteins at a conserved serine residue at position 5 regulates the ability of these proteins to antagonize bHLH-dependent gene expression [12]. It has also been shown that phospho-ablated Id2 Ala5 mutant where serine at position 5 is mutated to an Alanine is growth inhibitory in fibroblasts, smooth muscle cells and osteosarcoma cell lines $[12,22]$. Literature available also suggest that Id2-induced apoptosis is promoted through a mechanism different from what is used by other Id proteins. Studies also reveal that Id2-induced apoptosis is independent of HLH mediated dimerization and therefore independent on association with bHLH proteins [11]. Id2-induced apoptosis therefore is centered on the $\mathrm{N}$-terminal region of the protein and it is characterised by an enhanced expression of the pro-apoptotic BAX protein [5]. Enforced expression of the Id2 HB mutant in the HCT116 cells showed no difference in viability effect when compared with the wild-type Id2. In the Id 2 HB mutant (Helix Breaker), there is disruption of the HLH dimerization domain and this may explain why it behaves as a gain-of-function mutant when ectopically expressed. This observation can also be explained as the Id2 HB mutant is characterised by a drastically reduced ability to form stable heterodimers with bHLH proteins [27]. The results show that the phosphorylation characteristics of both $\operatorname{Id} 3$ and $\operatorname{Id} 2$ on growth and survival may be cell-type specific.

The western blot analysis shows that Id1, Id 2 and Id3 proteins are expressed in HCT116 cells as evident by their endogenous levels. Transient transfection with Id1, Id2, Id3 and Id4 resulted in the over-expression of these proteins when compared with their endogenous levels. Hence the effect of functional analyses of Id1, Id2, Id3 and Id4 in modulating apoptosis and cell cycle is influenced by the over-expression of these proteins. Regarding Id2 and Id3 wild-types and their respective mutants in terms of functional effects, the western blot analysis shows that the expression levels of the respective constructs are approximately equivalent. This observation suggests that differences in functional analysis in cross-comparing the mutants may not be attributed to differences in expression levels but as a result of an increase in their expression when compared to the endogenous levels of their respective wild-types.

\section{CONCLUSION}

The results from this study suggest that Id3 protein is pro-apoptotic in colorectal cancer cell lines (HCT116). However, recent data on primary Human Vein Umbilical Endothelial Cells show that over-expression of Id3, but not Id1 can protect HUVECs from apoptosis [15]. Hence Id3-induced apoptosis is shared in common with epithelial lineages but does not exhibit any proapoptotic effect in cells of endothelial lineage. On cell proliferation, over-expression of $\mathrm{Id} 3$ resulted in growth arrest in HCT116. Loss-or gain-of-function mutants of Id 2 and Id3 play essential roles in modulating cell growth and survival. With the Id2 mutants, Id2 Asp5 was only observed to be pro-apoptotic whilst Id 2 Ala5 and Id2 HB are gain-of-function mutants. These findings suggest that Id2 Asp5 may be loss-of-function mutant in HCT116 lines. In another development, the Aspartate mutant of Id3 (Id3 Asp5) was observed to be pro-apoptotic. However Id3 Ala5 and Id3 HB showed an anti-apoptotic effect, hence Id3 Asp5 may be a gain-of-function mutant whilst Id3 Ala5 and Id3 HB and Id3NLS may be described as loss-of-function mutants in HCT116. These results may suggest that Id 2 and Id3 may play essential roles in modulating human epithelial colon carcinoma growth and survival and could provide some hope for therapeutic opportunities in the treatment of colonic cancers.

\section{ACKNOWLEDGEMENTS}

The authors wish to acknowledge the contribution made by the gene regulation laboratory, and the molecular medicine group of the University of Essex. The authors also acknowledge Professor John D. Norton for the provision of the Id proteins (Id1Id4) and the aHLH constructs. The authors acknowledge the immense help received from scholars whose articles are cited and included in the references of this manuscript. The authors are also grateful to authors/editors/publishers of all those articles, journals and books from where the literature for this article has been reviewed and discussed.

\section{Financial support and sponsorship: Nil.}

Conflict of Interests: There are no conflicts of interest.

\section{REFERENCES}

1. Sikder HS, Meghann KD, Shariff D, Byungwoo R, Alani RM. Id proteins in cell growth and tumourigenesis. Cancer cell. 2003; 3:525530.

2. Askew DS, Ashmun RA, Simmons BC, Clevaland JL. Constitutive cmyc expression in an IL-3-dependent myeloid cell line suppresses cell cycle arrest and accelerates apoptosis. Oncogene. 1991; 6:19151922.

3. Wagner AJ, Kokontis MJ, Hay N. Myc-mediated apoptosis requires wild-type p53 in a manner independent of cell cycle arrest and the ability of p53 to induce p21 (WAF-1/CIP-1). Genes and Development. 1994; 8:2817-2830.

4. Chen X, Ko JK, Jayaraman L, Prives C. P53 levels, functional domains, and DNA damage determine the extent of the apoptotic response of tumor cells. Genes and Development. 1996; 10:2438 2451

5. Florio M, Hernandez MC, Yang H, Shu HK, Cleveland JK, Israel MA. Id2 promotes apoptosis by a novel mechanism independent of dimerisation to basic helix-loop-helix factors. Molecular and Cell Biology. 1998; 18:2371-2381. 
6. Wilson JW, Deed RW, Inoue T, et al. Expression of Id helix-loophelix proteins in colorectal adenocarcinoma correlates with p53 expression and mitotic index. Cancer Research. 2001; 61:8803-8810.

7. Nishiyama K, Takaji K, Kataoka K, et al. Id1 gene transfer confers angiogenic property on fully differentiated endothelial cells and contributes to therapeutic angiogenesis. Circulation. 2005; 112:2840-2850.

8. Parrinello S, Lin CQ, Murata K, et al. Id-1, ITF-2, and Id-2 comprise a network of helix-loop-helix proteins that regulate mammary epithelial cell proliferation, differentiation, and apoptosis. Journal of Biological Chemistry. 2001; 276:39213-39219.

9. Andres-Barquin PJ, Hernandez MC, Israel MA. Id genes in nervous system development. Histology and Histopathology. 2000; 15:603618.

10. Tanaka K, Pracyk JB, Takeda K, et al. Expression of Id1 results in apoptosis of cardiac myocytes through a redox-dependent mechanism. Journal of Biological Chemistry. 1998; 273:2592225928.

11. Norton JD. Id helix-loop-helix proteins in cell growth, differentiation and tumourigenesis. Journal of Cell Science. 2000; 113:3897-3905.

12. Hara E, Hall M, Peters G. CDK2-dependent phosphorylation of Id2 modulates activity of E2A-related transcription factors. European Molecular Biology Organization Journal. 1997; 16:101-110.

13. Kyei F. Knock-down of Id 1 and Id 3 proteins induces apoptosis in human colon carcinoma (HCT116) cells. Journal of Biology and Life Science. 2015; 6:194-208.

14. Kee BL, Rivera RR, Murre C. Id3 inhibits B lymphocyte progenitor growth and survival in response to TGF b. Nature Immunology. $2001 ; 2: 242-247$.

15. Sakurai D, Tsuchiya N, Yamaguchi A, et al. Crucial Role of Inhibitor of DNA binding/differentiation in the vascular endothelial growth factor-induced activation and angiogenic processes of human endothelial cells. Journal of Immunology. 2004; 173:5801-5809.

16. Hara E, Zebedee Z. Id proteins in cell cycle control and cellular senescence. Oncogene. 2001; 20:8317-8325.

17. Ling MT, Wang X, Ouyang XS, Xu K, Tsao SW, Wong YC. Id-1 expression promotes cell survival through activation of NF-B signalling pathway in prostate cancer cells. Oncogene. 2003; 22:4498-4508.

18. Barndt RJ, Zhuang Y. Controlling lymphopoiesis with a combinatorial E-protein code, Cold Spring Harbor Symposia on Quantitative Biology, New York, Cold Spring Harbor Laboratory Press; 1999, p 45-50.

19. Norton JD, Atherton GT. Coupling of cell growth control and apoptosis functions of Id proteins. Molecular Cell Biology. 1998: $18 ; 2371-2381$.
20. Tu X, Baffa R, Luke S, Prisco M, Baserga R. Intracellular redistribution of nuclear and nucleolar proteins during differentiation of 32D murine hemopoietic cells. Experimental Cell Research. 2003; 288;119-130.

21. Lasorella A, Iavarone A. The protein ENH is a cytoplasmic sequestration factor for Id 2 in normal and tumor cells from the nervous system. Proceedings of the National Academy of Sciences USA. 2006; 103;4976-4981.

22. Matsumura ME, Lobe DR, McNamara CA. Contribution of the helixloop- helix factor Id2 to regulation of vascular smooth muscle cell proliferation. Journal of Biological Chemistry. 2002: 277:7293-7297.

23. Li X, Luo Y, Starremans PG, McNamara CA, Pei Y, Zhou J. Polycystin-1 and polycystin-2 regulate the cell cycle through the helix-loop-helix inhibitor Id2. Nature Cell Biology. 2005; 7:11021112.

24. Xu L, Massague J. Nucleocytoplasmic shuttling of signal transducers. Nature Reviews Molecular Cell Biology. 2004; 5:209. 219.

25. Deed RW, Hara E, Atherton GT, Peters G, Norton J. D. Regulation of Id3 cell cycle function by Cdk2-dependent phosphorylation. Molecular Cell Biology. 1997; 17:6815-6821.

26. Butler DC, Haramizu S, Williamson D. L, Always S. E. Phosphoablated Id2 is growth suppressive and pro-apoptotic in proliferating myoblasts. PloS One. 2009; 4: e6302.

27. Deed WR, Jasiok M, Norton JD. Lymphoid-specific expression of the Id3 gene in hematopoietic cells: selective antagonism of E2A basic helix-loop-helix protein associated with Id3-induced differentiation of erythroleukaemia cells. Journal of Biological Chemistry. 1998; 273:8278-8286.

\section{How to cite this article:}

Kyei F, Asante D, Sarpong E, Edekor J.A.M, Konja D, Gavor E. Over-expression of Id2 and Id3 Proteins Regulates Growth and Survival of Human Colon Carcinoma (HCT116) Cells. J App Biol Biotech. 2017; 5 (01): 010-017. DOI: 10.7324/JABB.2017.50102 